\title{
«Recertification»: ein kurzer Bericht über ein sympathisches Ereignis
}

Kurt Bösch

Korrespondenz:

Dr. med. Kurt Bösch Postfach, Schlossbach 9404 Rorschacherberg

kuboesch@paus.ch
Man wird gerne gefeiert. Auch mit 80 und drüber.

Die Basler Fakultät hat mich und viele andere, alle mindestens 80jährig, zum 50. Doktorjubiläum eingeladen. Wer vor mindestens 50 Jahren promovierte, war willkommen. Leider blieb verborgen, wie viele Personen angeschrieben worden sind, wie viele nicht zu kommen vermochten, wie vielen dieses Ereignis nichts sagte und wie viele leider nicht mehr am Leben sind. Schliesslich entstand immerhin eine Teilnehmerliste mit 56 Nennungen. Also immer noch eine stattliche Zahl. Da im Gefolge der Ideologien der 68er Jahre (wie wir vernehmen konnten mit Verzicht auf Tradition, dementsprechend Abschaffung von Jubiläen und demzufolge Einsparung von Druck- und Portokosten) nie mehr gefeiert worden war, waren Promovierte aus früheren Jahren bis zum echten Jubiläumsjahr 1956 zugegen. Wenn ich recht hingehört habe, gab es sogar eine Jubilarin aus den Jahren 1943 (Gret Nicole-Gysler) im Saal. Jeder Anwesende konnte Kommilitonen begrüssen, die er seit 40, ja 50 Jahren nicht mehr gesehen hatte, der Edi Kloter war da, Georges Hauser, Ernst Hochuli, Dölf Sutter, Helmut Stahl und Gattin ... darunter neun Professoren von Rang, Rodolphe Meyer, Georges-André Hauser, Martin Schmid, Robert Hess, Kurt Siegfried Ludwig, Peter Paul Waibel, Ernst Hochuli, Karl Pfeiffer und Max Just.

Man hat sich rührend um uns bemüht. Jeder bekam seinen reservierten Platz im Hörsaal Nr. 102 des Kollegienhauses, an dem er sein Diplom hätte entgegennehmen sollen. Aber ein Teil - man wird im Alter nicht selten störrisch der Geladenen kümmerte sich wenig um Sitzordnung und Organisation und stellte damit Anforderungen an das Improvisationstalent von Frau Notaro, der Sekretärin der Alumnivereinigung, die zusammen mit dem rührigen, um jeden von uns besorgten Dr. Fröscher, seines Zeichens Sekretär der Alumnivereinigung, sonst alles wohl im Griff hatte. Begrüsst wurden wir vom Geschäftsführer der Alumnivereinigung, Prof.

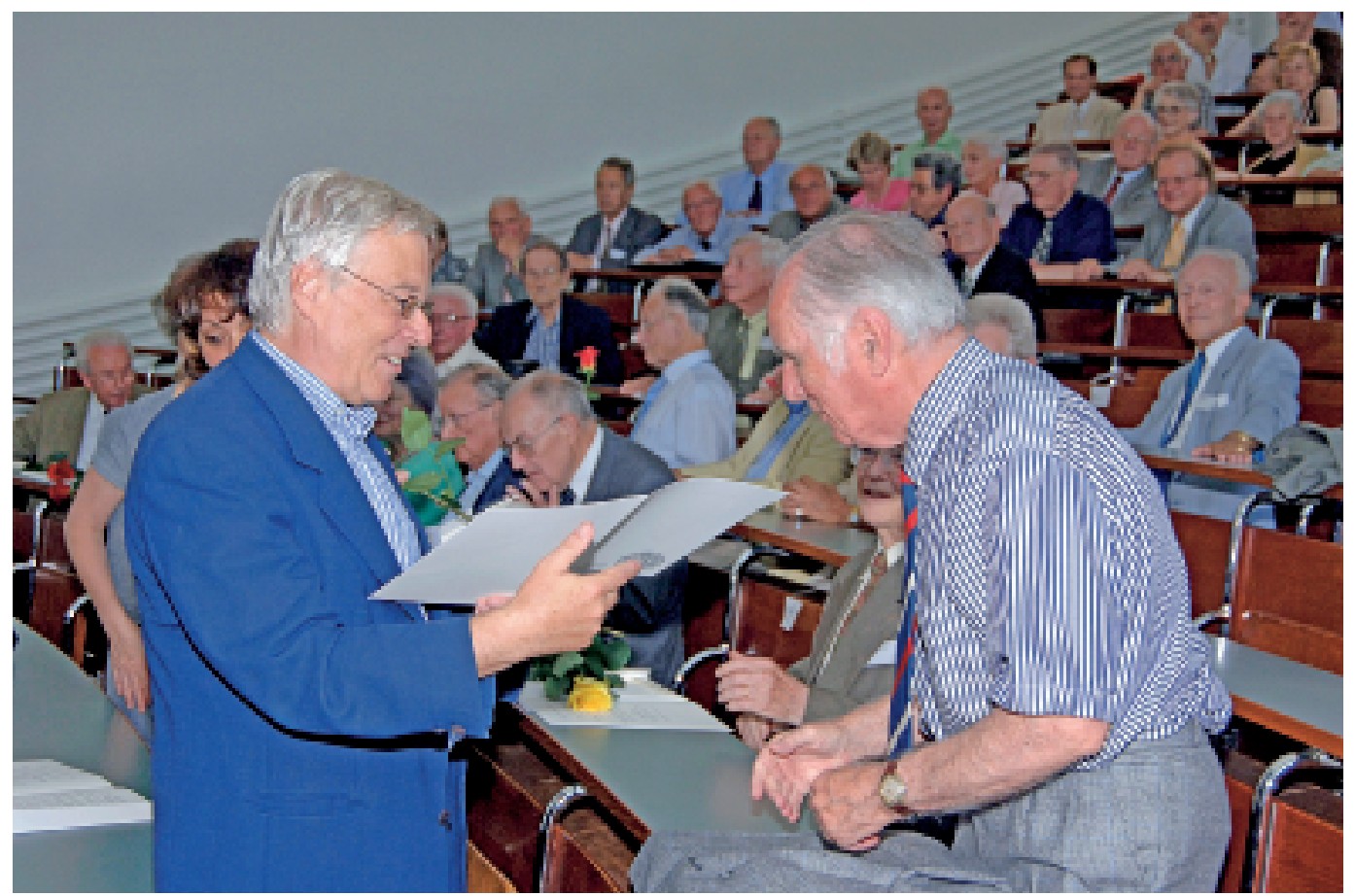

Dekan, Prof. Perruchoud, überreichte die Diplome. 
Michael Mihatsch, persönlich und Dekan Prof. André Perruchoud machte uns mit den geänderten Strukturen der Medizinischen Fakultät und deren Politik, nicht ohne Seitenblicke auf den Zürcherischen Herrschaftsanspruch, vertraut. «Die Vergangenheit ist das Rüstzeug, das uns hilft, unsere Zukunft zu gestalten», schrieb Ortega y Gasset. Prof. Perruchoud macht bekannt, dass er selber auch bald ein Diplom erhoffe, da sein Rücktritt bevorsteht. Die Diplome überreichte der Dekan eigenhändig und mit Handschlag.

Und dass ich's nicht vergesse: Die musikalische Umrahmung war durchaus altersgerecht, aber nur was das Alter (das sie dem unsrigen gleichsetzte) der quirligen Bluessängerin Othella Dallas betraf, die unter Lebensgefahr quasi als Showeinlage ihre Songs, brillant begleitet von Christian Gutfleisch am Keyboard, hoch oben von einem elegant-beschwerlich erklommenen Stuhl zum besten gab. Die Besteigung gar der Pulte wurde ihr vorsorglich von Herrn Mihatsch verwehrt. Auch auf halber Höhe hielt er sie schützend im Auge, gleich einem Aufpasser in der Zirkusarena. Es gelang ihm damit, Schlimmes zu verhüten.

In den Anlass eingebettet wurde die Verleihung des Dora-Seif-Preises 2006 an Prof. Giulio Spagnoli und die Prämierung der besten Publikation 2005 von Prof. Dr. rer. nat. Rudolf Brenner und PhD Pascal Escher. Ihre bereichernden Refe- rate in Englisch und Deutsch überstiegen z.T. den Wissensstand und das Auffassungsvermögen der Anwesenden.

Gerne danke ich, herzlich und ungeheissen, im Namen aller Teilnehmer Herrn Dr. Fröscher, Prof. Mihatsch, dem Dekan Prof. Perruchoud und Frau Notaro für die freundliche Einladung, für die ungezwungene Durchführung und nicht zuletzt auch für den Apéro, der in die Alumnitagung der Basler Universität überführte.

Nichts gegen die Alumnivereinigung getauften Ehemaligenkollektive, die man an verschiedenen Orten findet; ich gehöre selber mehreren solcher Zirkel an. Aber, Alumnus war ursprünglich, dem Langenscheidt und dem Wahrig entsprechend, ein «Zögling» einer Einrichtung zur geistlichen Ausbildung. Später wurde dieser Zögling aus unerklärlichen Gründen zum Ehemaligen und, wenn ich mir bei dieser Gelegenheit die Bemerkung erlauben darf, man folgte in Europa, wie so oft, eilfertig dem wohlbekannten semantischen Unverstand der Amerikaner, wie zum Beispiel auch beim Bachelor.

Nicht alle Teilnehmer der Doktordiplomfeier sind (oder waren) «Alumni», weshalb sich die Reihen lichteten und männiglich seinem Auto oder dem Tram und der SBB zustrebte.

Was ich denn nun mit meinem neuerworbenen Diplom zu tun gedenke? Klar, ich eröffne demnächst eine neue Praxis. 